\title{
Drug-induced changes in responding are dependent on baseline stimulus-reinforcer contingencies
}

\author{
DAVID N. HARPER \\ Victoria University, Wellington, New Zealand
}

\begin{abstract}
The disruptive effect of four drugs was examined using a multiple-schedule procedure that allowed the assessment of behavioral resistance to change. With rats as subjects, responding in one component was maintained on a variable-interval (VI) 30-sec schedule, and responding in the other components was maintained using a VI 30-sec schedule that operated concurrently with a variable-time 30-sec schedule. Quinpirole and fluoxetine, but not $d$-amphetamine, resulted in greater changes relative to baseline for responding in the component associated with the weaker stimulus-reinforcer contingency (VI 30-sec component). This effect is consistent with the view that the degree to which dopaminealtering drugs change responding is dependent on the strength of the baseline stimulus-reinforcer contingencies as opposed to the baseline response-reinforcer contingencies. In contrast, the assessment of $d$-amphetamine in terms of resistance to change was confounded by a simultaneous weakening of stimulus control that interfered with the stimulus-reinforcer contingencies established across the levers.
\end{abstract}

Research examining behavioral resistance to change has demonstrated that the extent to which food-reinforced responding is disrupted by events such as reducing the maintaining reinforcement schedule to extinction, delivering response-independent food between multiple-schedule components, or prefeeding subjects prior to a session is dependent on baseline levels of reinforcement. Specifically, the greater the level of reinforcement associated with responding in a component, the less that responding is disrupted relative to its baseline level (Harper, 1996; Harper \& McLean, 1992; Nevin, 1974; Nevin, Mandell, \& Atak, 1983; Nevin, Tota, Torquato, \& Shull, 1990).

Although both rate of responding and its resistance to change are dependent on the rate, magnitude, and delay of reinforcement (Nevin, 1974), Nevin and colleagues (Nevin, 1984, 1992; Nevin et al., 1983; Nevin et al., 1990) have argued that rate of responding and resistance to change are independent dimensions of behavior. This argument is based on the observation that rate of responding is determined by response-reinforcer contingencies, but resistance to change is determined by stimulus-reinforcer contingencies. For example, Nevin et al. (1990) trained pigeons on multiple-schedule components in which the variable-interval (VI) schedules were identical, but in some conditions, alternative reinforcers were also arranged concurrent with one of the components on a variabletime (VT) schedule. The additional VT reinforcers weak-

This research was supported by Internal Grants Committee funding from Victoria University, Wellington. The manuscript was prepared while D.N.H. was based at the University of Wales, Cardiff. Correspondence should be addressed to D. N. Harper, Department of Psychology, Victoria University, P.O. Box 600, Wellington, New Zealand (e-mail: david.harper@vuw.ac.nz). ened the response-reinforcer contingency for the concurrent VI VT component relative to the VI-only component. However, VT reinforcers simultaneously increased the amount of food available during the VI VT component, thus increasing the contingency between the stimuli signaling this component and reinforcement relative to the VI-only component. Consistent with the claim that resistance to change depends on the strength of the stimulusreinforcer contingency associated with a given behavior, Nevin et al. (1990) found that although the absolute rate of responding was lower in the VI VT component, the resistance to prefeeding and extinction was greater.

Although many different forms of disruption have been shown to produce effects consistent with the claim that responding associated with stronger stimulus-reinforcer contingencies is more resistant to disruption, one area of debate has been with respect to the disruptive effects of drugs on reinforced responding. For example, the findings of Egli, Schaal, Thompson, and Cleary (1992) support the suggestion that drugs can be viewed as disruptive influences acting on reinforced responding in the same way as extinction, prefeeding, or response-independent food. They examined changes in response rates in multipleschedule components following administration of opioid drugs. Their data supported the conclusion that the extent of disruption to responding was dependent on the dose of the drug (greater doses led to greater disruption) and rate of reinforcement maintaining responding (responding changed relatively less in components associated with higher reinforcer rates). In contrast, Cohen (1986) demonstrated that although a variety of different drugs could reduce response rates relative to baseline levels, they did not necessarily result in a relatively greater reduction for responding maintained by longer delays to reinforcement 
or lower rates of reinforcement. Cohen interpreted these findings as demonstrating that many of the commonly used drugs for altering responding (such as haloperidol and $d$-amphetamine) might not alter reinforced responding in a manner analogous to response-independent food, prefeeding, and extinction.

A possible problem in interpreting the findings of Egli et al. (1992) and Cohen (1986) in terms of resistance to change concerns the effects that drugs may have on stimulus discrimination. Generally, in the resistance-to-change literature disruptors are thought of as devaluing the experimental reinforcer (relative to other sources of reinforcement; see Nevin et al., 1990). However, drugs may, in addition, degrade the stimulus control exerted by the stimuli that signal components. Degraded stimulus control would, on its own, result in increased responding in the component where reinforcement contingencies make responding lower (the leaner component in both the Egli et al. and Cohen studies) and decreased responding in the alternate richer component. Because of this possible confounding effect on stimulus control, the disruption caused by a drug might not be reflected in a greater reduction in responding, relative to baseline, in the leaner component.

Furthermore, in the Egli et al. (1992) and Cohen (1986) studies, the role of stimulus-reinforcer contingencies could not be separated from the role played by responsereinforcer contingencies in determining resistance to drug-induced changes in responding. In both studies, the behavior maintained by the strongest response-reinforcer contingency also occurred in the presence of the discriminative stimuli associated with the strongest stimulusreinforcer contingency. Consequently, not only was the rate of reinforcement higher in the most resistant component, but also the baseline rate of responding. Therefore, it is not possible to determine whether the extent of behavioral change in a given component was directly dependent on baseline reinforcement per se (as claimed by Nevin et al., 1990) or on the rate of responding established in baseline. This issue is particularly relevant in the examination of drugs such as $d$-amphetamine or antipsychotics, which alter dopamine levels in the brain. Some researchers have claimed that the extent of change in reinforced responding following delivery of such drugs is dependent on baseline reinforcer levels (e.g., Heyman, 1983; Heyman \& Seiden, 1985), while others have claimed that the extent of change depends on baseline response rate (e.g., Dews \& Wenger, 1977; Lucki \& DeLong, 1983). If the disruptive effect caused by such drugs is to be interpreted in terms of Nevin's concept of resistance to change, the behavioral procedure employed to examine responding needs to separate the role played by stimulusreinforcer versus response-reinforcer contingencies.

One way to determine whether it is the baseline stimulus-reinforcer contingency or baseline responsereinforcer contingency that is critical for determining subsequent resistance to drug-induced disruption is to use Nevin et al.'s (1990) method of arranging multiple- schedule reinforcer delivery. In this procedure, one target component is simultaneously associated with a low response-reinforcer contingency but a relatively high stimulus-reinforcer contingency. In the other component, responding occurs at a higher rate (because it is associated with a relatively high response-reinforcer contingency) but is simultaneously associated with a relatively lower stimulus-reinforcer contingency than that established in the first component. Such an approach was taken in a recent study by Harper (in press) in order to examine the disruptive effects of the antipsychotic drugs haloperidol and clozapine on reinforced responding in rats. Harper (in press) found that both drugs reduced responding to a greater extent, relative to baseline, in the component associated with the lowest overall amount of reinforcement. Thus, it was concluded that the extent of reduction in responding caused by these drugs depended on stimulusreinforcer strength and not on the baseline responsereinforcer contingency or baseline rate of responding.

In light of Harper's (in press) findings with antipsychotics and the problems in interpreting the findings of some previous studies, it is worthwhile examining the effects of drugs that increase (as opposed to decrease) dopamine levels in the brain. The neurotransmitter dopamine is of interest with respect to the role it plays in the reinforcement process because stimuli that increase dopamine activity (e.g., drugs such as $d$-amphetamine or electrical stimulation of the medial forebrain bundle) can increase the efficacy of food reinforcement in maintaining responding (Heyman, 1983; Heyman \& Seiden, 1985) or even act as effective reinforcers themselves (Olds \& Fobes, 1981; Wise \& Bozarth, 1987). Drugs that block dopamine activity (e.g., antipsychotics), by contrast, reduce the effectiveness of reinforcers in maintaining responding (Fouriezos \& Wise, 1976; Heyman, 1983; Heyman, Kinzie, \& Seiden, 1986; Rolls et al., 1974).

Part 1 examined the effects of $d$-amphetamine on responding. Amphetamine was chosen because different interpretations exist regarding this drug's effects on reinforced responding (e.g., Heyman, 1983; cf. Cohen, 1986). Whereas Heyman's results indicate that responding increases more in components associated with lower rates of reinforcement versus higher rates of reinforcement, Cohen's results suggest that the extent of change is similar across components of different reinforcer rates. A reexamination of $d$-amphetamine's effects on responding in terms of resistance to change was aimed at clarifying this debate. Part 2 sought to replicate and further refine the findings of Part 1 by examining the effects of quinpirole, a relatively specific dopamine agonist at the D2 receptor site. Quinpirole was chosen because, similar to $d$-amphetamine, it is a dopamine agonist (and is therefore likely to have a similar effect on responding), but it is more specific in terms of its site of action in the nervous system. Finally, in Part 3, the effects of the serotonin re-uptake inhibitor, fluoxetine, were examined. As with $d$-amphetamine and quinpirole, the aim was to examine whether changes in responding were greater for re- 
sponding occurring in a component associated with a relatively weaker stimulus-reinforcer contingency. However, in the case of fluoxetine, the enhancement of dopamine is indirect in that its primary site of neural action is an enhancement of serotonin levels, which, in turn, cause a facilitation of dopamine levels (Gardier et al., 1994; Steckler \& Sahgal, 1995).

In order to examine the effects of the drugs on resistance to change as well as the role played by stimulus-reinforcer contingencies on that resistance, the present study used the method of arranging multiple schedules used by Nevin et al. (1990) and Harper (in press). In each part of the present research, the main question was whether responding in a given component changes relatively more (either in terms of an increase or decrease beyond baseline levels) if that responding occurs in the presence of a stimulus associated with a relatively low overall reinforcer rate.

\section{METHOD}

\section{Subjects}

Five male Norway hooded rats, approximately 4 months old at the start of training, were maintained at $85 \%$ of their free-feeding bodyweights. Prior to the experimental conditions being conducted, rats were trained to lever-press for food reinforcement and had received 3 months of training in the multiple-schedule procedure described below. Supplementary feed was given after each session of training to maintain prescribed body weights. Rats were housed in pairs, with water and untreated wood shavings available continuously in their homecages. The housing room was maintained at a constant $22^{\circ} \mathrm{C}$ with lights on between 7 a.m. and 7 p.m.

\section{Apparatus}

Rats were trained individually in a single experimental chamber (measuring $31 \times 32 \times 24 \mathrm{~cm})$. A red stimulus light $(12 \mathrm{~W}$ ) was situated above each of two response levers. One lever was located on the left side of the front wall and the other was located on the right side. Reinforcers $(0.1 \mathrm{ml}$ of a mixture of $15 \%$ sweetened milk and $85 \%$ water) were delivered via a dipper mechanism located in the center of the front wall. Reinforcers remained available until collected. All experimental events were scheduled and recorded by an IBM-compatible computer running MED-PC software in a room remote from the experimental chamber.

\section{Behavioral Procedure}

Experimental sessions were conducted daily, 7 days per week, and comprised 26 multiple-schedule components presented equally often and in a pseudorandom order. Target components (during which responding was reinforced) were $60 \mathrm{sec}$ in duration and signaled by illuminating the light above either the left or the right lever. Components were separated from one another by a 30-sec intercomponent interval (i.e., no stimulus lights were lit and responding on levers was not reinforced). During left-lever components a VI 30 -sec and a VT 30-sec schedule were both concurrently in effect. During right-lever components, a single VI 30 -sec schedule was in effect. Therefore, during the left-lever component, approximately half of the reinforcers were delivered contingent on leverpressing, and approximately half of the reinforcers were delivered noncontingently with leverpressing. During the right-lever component, reinforcers were only delivered contingent with leverpressing. In total, half as many reinforcers were scheduled for the right-lever component than for the left-lever component. Analysis of the number of reinforcers actually obtained across all conditions at the end of the experiment showed that the mean number of reinforcers de- livered was $\mathbf{4 4 . 7}$ during the left-lever component and 21.8 during the right-lever component. During reinforcer delivery, component and reinforcement schedule timing were suspended. Rats received 90 sessions of training in this procedure and at these schedule values prior to the introduction of the experimental probe sessions described below.

For the first three experimental sessions of Part 1, rats were presented with response-independent food delivered during the intercomponent interval arranged on a VT 15-sec schedule. Intercomponent food was delivered in the same manner as reinforcers for responding (i.e., sweetened milk delivered via the dipper mechanism). The three probe sessions of intercomponent food delivery were conducted with six normal baseline sessions occurring between sessions. The purpose of this condition was to verify that the baseline training had established greater resistance to disruption in the component associated with the greatest overall amount of reinforcement (the left-lever component).

\section{Drug Procedure}

Part 1 examined the disruptive effects of $d$-amphetamine on reinforced responding in the multiple-schedule procedure described above; $d$-amphetamine was dissolved to the appropriate dose in $0.9 \%$ saline prior to administration. Injections were delivered $1 \mathrm{ml} / \mathrm{kg}$ i.p. approximately $10 \mathrm{~min}$ prior to an animal being placed in the response chamber. Injections were given only on Tuesdays and Fridays. On days when drugs were not delivered, rats were still trained in the multiple-schedule procedure. Doses of $d$-amphetamine were delivered in the following order across experimental sessions: $0.3 \mathrm{mg} / \mathrm{kg}, 3.0 \mathrm{mg} / \mathrm{kg}, 0.0 \mathrm{mg} / \mathrm{kg}$ (saline control), and $1.0 \mathrm{mg} / \mathrm{kg}$. This sequence of drug delivery sessions was repeated three times, with a week in between each repetition.

Part 2 examined the effects of the relatively specific D2 agonist quinpirole on responding in the present procedure. Quinpirole injections were given in the following order: $0.025 \mathrm{mg} / \mathrm{kg}, 0.0125 \mathrm{mg} / \mathrm{kg}$, $0.0 \mathrm{mg} / \mathrm{kg}, 0.05 \mathrm{mg} / \mathrm{kg}$, and $0.0075 \mathrm{mg} / \mathrm{kg}$. This sequence was repeated twice with 1 week between repetitions. Finally, Part 3 examined the effects of the 5-HT re-uptake inhibitor fluoxetine on responding. The doses of fluoxetine were $1.0 \mathrm{mg} / \mathrm{kg}, 0.0 \mathrm{mg} / \mathrm{kg}$, $0.5 \mathrm{mg} / \mathrm{kg}$, and $2.5 \mathrm{mg} / \mathrm{kg}$. This sequence was repeated twice with 1 week between repetitions. The preparation and drug administration procedures for quinpirole and fluoxetine were the same as for $d$-amphetamine in Part 1 .

\section{Measurement of Behavior}

In order to examine the resistance of responding to disruption, responding in a single experimental probe session was expressed relative to the number of responses made in the immediately preceding baseline session (i.e., when no drug was delivered). This proportion of baseline responding was calculated separately for responding on the appropriate lever in the left- and right-lever components. The values obtained in this manner measure the extent of change in responding following administration of a drug relative to a baseline level of responding in a given multiple-schedule component. These values were then averaged across repetitions of each drug at a given dose. The obtained value was then log transformed in order to show the extent to which responding either increased or decreased relative to zero (i.e., a value greater than zero indicates an increase in responding, whereas a value less than zero indicates a decrease in responding).

In addition to recording the responses made on the appropriate lever during each component, the number of responses made on the alternate/unsignaled lever was also recorded (e.g., left-lever responses during illumination of the light signaling the right-lever component). The purpose of this measure was to examine whether stimulus control was degraded by drug delivery. That is, did drugs impair the ability of rats to respond on the appropriate lever when a given component was signaled? 


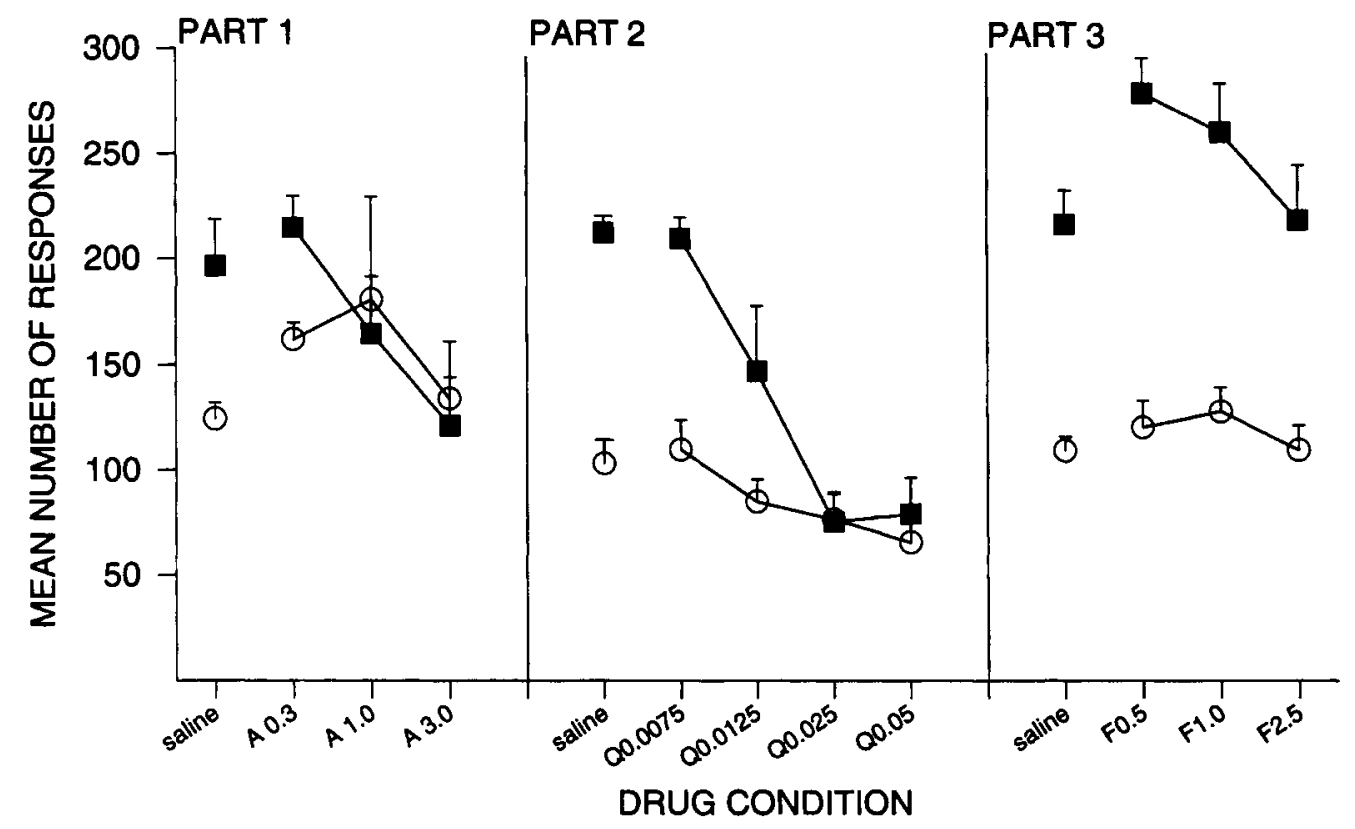

Figure 1. Mean number of responses made in a session (across all subjects) for each condition of Parts 1, 2, and 3 . Unfilled circles represent responses made during the left-lever component, and filled squares represent responses made during the right-lever component. $A, d$-amphetamine; $Q$, quinpirole; $F$, fluoxetine. Error bars show the standard error of the mean.

\section{RESULTS}

By the end of the initial period of training, all rats were displaying a pattern of responding that was consistent with their having learned to discriminate between the multiple-schedule components. Figure 1 shows the overall group mean number of responses made in left-lever and right-lever components during each drug condition. Across the three control saline conditions, responding averaged between 103 and 125 for responses made during the left-lever component (overall richer reinforcement but with weaker response-reinforcer contingency) and between 179 and 213 for the right-lever component (overall leaner reinforcement but with stronger responsereinforcer contingency). Every individual rat displayed the same pattern of responding as the overall group pattern-that is, a greater absolute level of responding in the left-lever component relative to the right-lever component. This pattern was evident throughout the entire experiment for sessions that did not involve disrupting performance.

Also consistent with the existence of the appropriate stimulus control during baseline and control saline sessions was the extent to which rats responded on the inappropriate lever during each component. Figure 2 shows the overall group mean number of responses made to the right lever during the left-lever component and to the left lever during the right-lever component for each drug condition. In the control saline conditions and baseline sessions (not shown), responding on the inappropriate lever was typically fewer than 10 responses in an entire session.

\section{Part 1}

Consistent with previous findings (e.g., Harper, 1996; Harper \& McLean, 1992), when responding was disrupted using delivery of response-independent food during the intercomponent interval, there was a greater resistance to change for responding in the component associated with overall richer reinforcement (left-lever component). Figure 3 shows the log proportion of responses made in each component for each condition in Part 1. When response-independent food was delivered during the $30-\mathrm{sec}$ intercomponent interval, responding decreased in both components. Specifically, the mean proportions of baseline responses made in a session were .83 and .64 in the left versus right components, respectively. Therefore, the decrease in responding was greater, relative to baseline, in the right-lever component versus the left-lever component, a pattern that was observed in all subjects.

When $d$-amphetamine was used to change responding, however, there was no consistent difference between leftand right-lever component responding with respect to resistance to change. Although 1 rat (R15) showed changes in responding consistent with the possibility that responding in the right component was more susceptible to change, most of the rats did not show consistent changes across doses. In R15, for example, when overall responding increased (at $0.3 \mathrm{mg} / \mathrm{kg}$ ), this increase was relatively greater in the right-lever component. When over- 


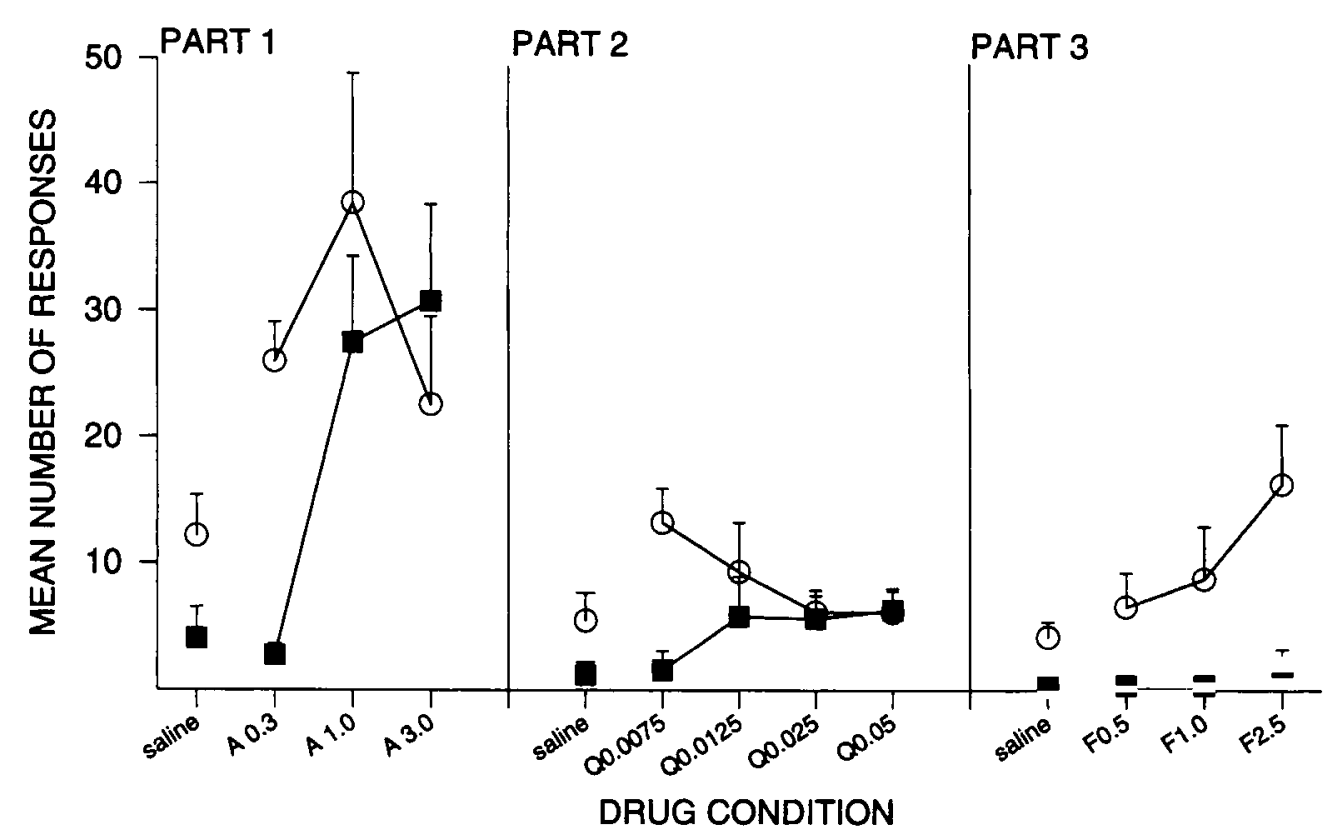

Figure 2. Mean number of responses made (across all subjects) on the unsignaled lever during each component in Parts 1, 2, and 3. Unfilled circles represent responses made to the right lever during the left-lever component and filled squares represent responses made to the left lever during the right-lever component. A, $d$-amphetamine; $Q$, quinpirole; F, fluoxetine. Error bars show the standard error of the mean.

all responding decreased (at 1.0 and $3.0 \mathrm{mg} / \mathrm{kg}$ ), the decrease was, again, relatively greater in the right-lever component. In contrast, however, R11 and R12 displayed only a relatively small and inconsistent difference between the extent of change in left versus right lever responding when overall responding either increased or decreased. Furthermore, in several instances, responding in the left-lever component changed to a greater extent than responding in the right-lever component (e.g., R12, $\mathrm{R} 13$, and $\mathrm{R} 14$ at the $1.0-\mathrm{mg} / \mathrm{kg}$ dose).

Figure 2 shows that, in addition to decreasing overall target-component responding, $d$-amphetamine also caused a disruption to the stimulus control exerted by the stimuli signaling the target component. At the lowest dose, amphetamine resulted in an increase in responses made to the right lever during the signaling of the left-lever component. At the $1.0-$ and $3.0-\mathrm{mg} / \mathrm{kg}$ doses there was an increase in the number of responses made to both the right lever during the signaling of the left-lever component and to the left lever during the signaling of the rightlever component.

\section{Part 2}

Figure 4 shows the log proportion of responses made in each component for each condition in Part 2. An examination of the data presented in Figure 4 reveals that the dopamine agonist quinpirole caused a dose-dependent decrease in responding. Although the lowest dose did not produce a consistent change in responding, the next lowest dose $(0.0125 \mathrm{mg} / \mathrm{kg})$ caused an overall decrease in re- sponding relative to baseline in all subjects. This decrease in responding was consistently greater in the right-lever component (a mean proportion of baseline of $.84 \mathrm{vs} .69$ in the left vs. right components). As the dose increased further, all subjects showed progressively greater overall decreases in responding, and all subjects showed considerably greater decreases in the right-lever component than in the left-lever component. Thus, at the highest dose, the mean proportion of baseline responding in the left component was .66 versus .31 in the right-lever component.

\section{Part 3}

Figure 5 shows the log proportion of responses made in each component for each condition in Part 3. An examination of the data presented in Figure 5 reveals that of the doses of fluoxetine tested, only $0.5 \mathrm{mg} / \mathrm{kg} \mathrm{had}$ an obvious effect on responding. At this dose, overall responding increased relative to baseline, and this increase was greater in the right-lever component for all subjects (a mean proportion of baseline of $1.36 \mathrm{vs.} 2.17$ in the left vs. right components). Although there was a slight overall increase in responding at the next highest dose $(1.0 \mathrm{mg} / \mathrm{kg})$, this was not consistent across individual subjects, nor was the increase necessarily greater in one component versus the other.

\section{DISCUSSION}

The present study assessed whether drug-induced increases and decreases in responding are dependent on 


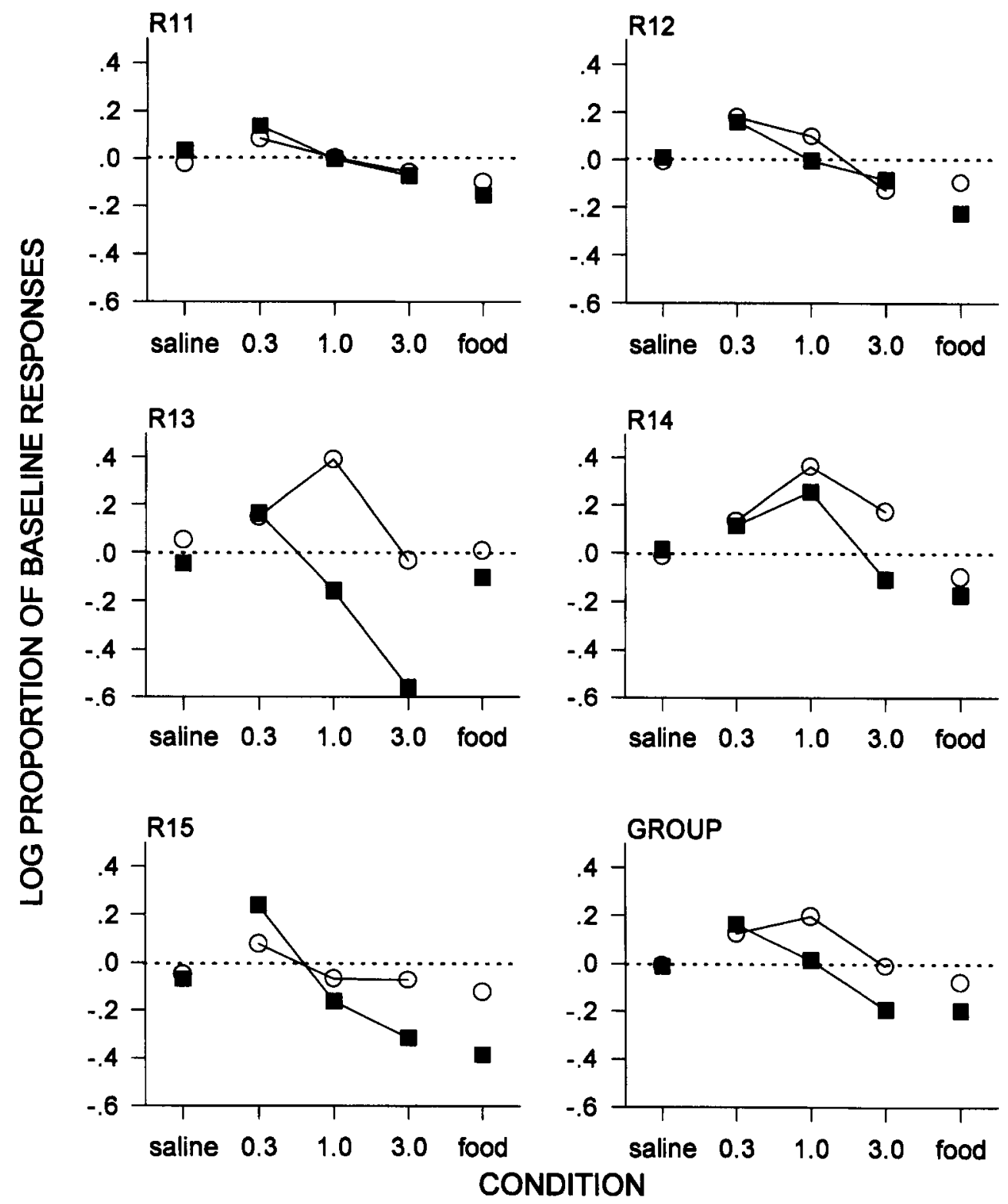

Figure 3. Log proportion of baseline responding in the left-lever (unfilled circles) and right-lever (filled squares) components as a function of the dose of $d$-amphetamine for each subject and the group as a whole in Part 1. Also shown is the log proportion of baseline responding following delivery of responseindependent food during the intercomponent interval.

the strength of the baseline stimulus-reinforcer contingency associated with responding. At the lower doses, both fluoxetine and $d$-amphetamine produced systematic increases in responding across all subjects. Only fluoxetine, however, produced increases in responding dependent on baseline stimulus-reinforcer contingencies. That is, responding increased more in the component associated with the relatively weaker stimulus-reinforcer contingency. Fluoxetine's effect on responding was consistent with the effects of drugs that produce a decrease in responding (e.g., quinpirole here; clozapine and haloperi- dol previously) in that the extent of response change was determined by baseline stimulus-reinforcer contingencies, albeit with the change in responding now being an increase as opposed to a decrease. These drug effects are consistent with a considerable body of literature that has explored reinforcer-based forms of disruption such as delivery of food between components (e.g., Harper, 1996; Harper \& McLean, 1992; Nevin, 1974, 1992).

A major exception to the suggestion that drugs can disrupt reinforced responding in a manner analogous to reinforcer-based disruptors appears to be the effects of $d$ - 


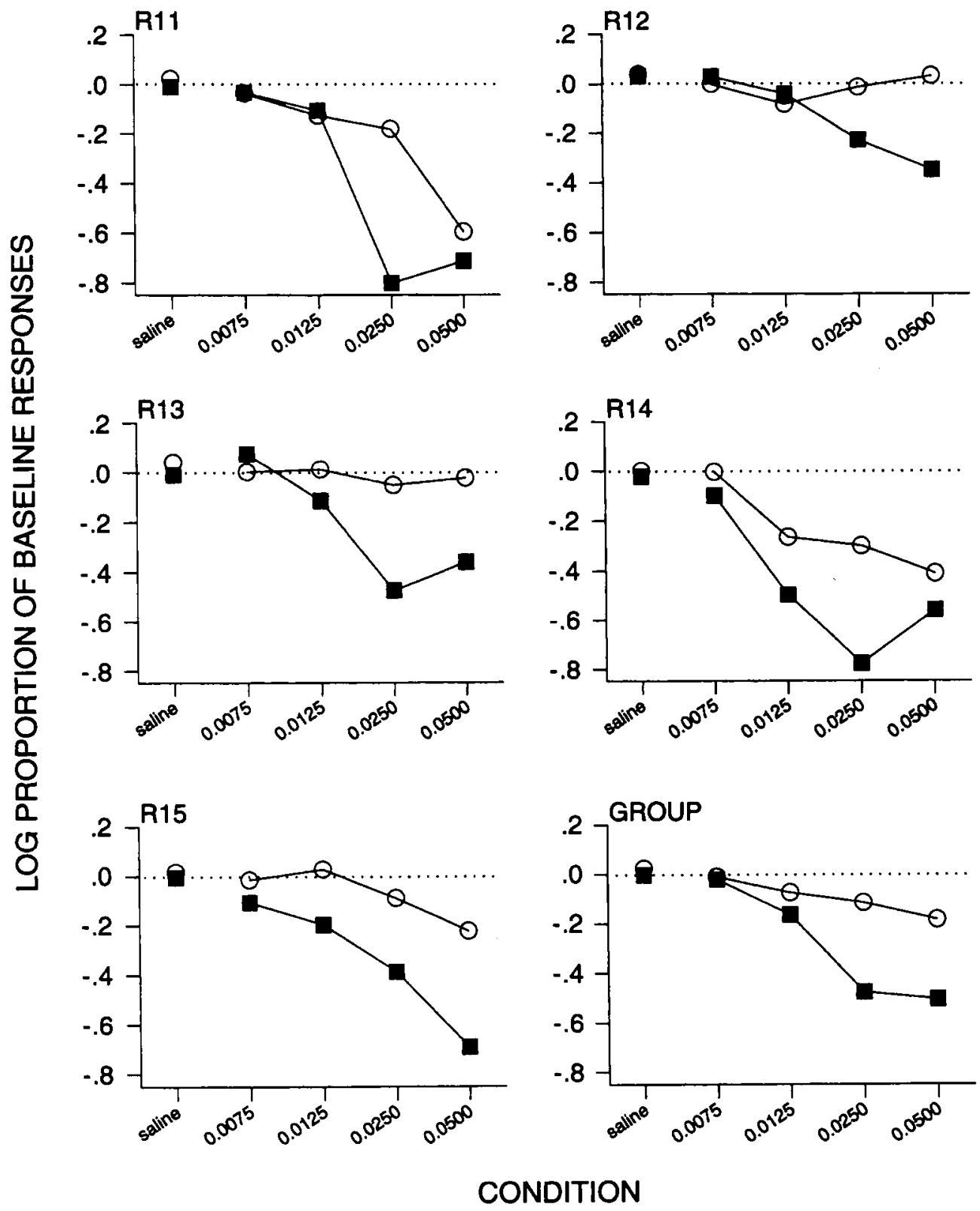

Figure 4. Log proportion of baseline responding in the left-lever (unfilled circles) and right-lever (filled squares) components as a function of the dose of quinpirole for each subject and the group as a whole in Part 2.

amphetamine. In both the present study and a previous one by Cohen (1986), $d$-amphetamine was able to induce significant increases and decreases in responding at low and high dose levels, respectively. In contrast to the other drugs examined here, the extent of the increase or decrease in responding was not dependent on the baseline levels of reinforcement. A closer examination of $d$ amphetamine's effects in the present task, however, indicates that $d$-amphetamine may have had several different effects on responding, which confounded its assessment in terms of resistance to change.
A potential problem in assessing $d$-amphetamine's effect on reinforced responding stems from the observation that this drug has multiple sites of action in the brain. Although $d$-amphetamine's action on dopamine in the mesolimbic pathway and nucleus accumbens has been associated with its effects on reinforcement processes (Ljungberg, Apicella, \& Schultz, 1992; Philips, Willner, \& Muscat, 1991; Taylor \& Robbins, 1984; Wise, 1982), amphetamine also alters basic motor function, possibly via its actions on dopamine in the nigrostriatal pathway (Lyon \& Robbins, 1975; Philips et al., 1991; Salamone, 


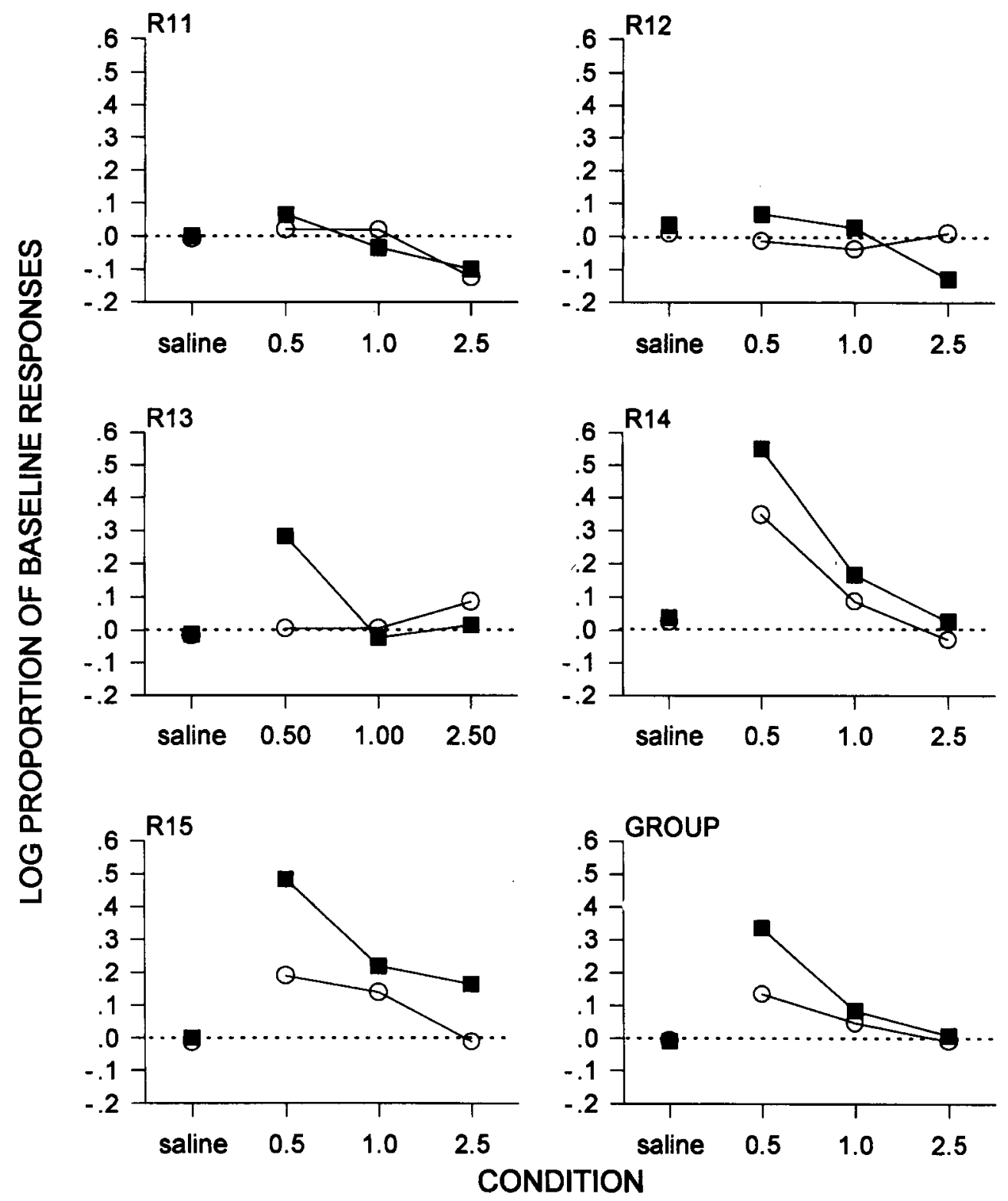

Figure 5. Log proportion of baseline responding in the left-lever (unfilled circles) and right-lever (filled squares) components as a function of the dose of fluoxetine for each subject and the group as a whole in Part 3.

Kurth, McCullough, \& Sokolowski, 1995; Sanger, 1986). Quantitative analyses have shown that drug-induced increases or decreases in dopamine levels alter both reinforcement efficacy and motor processes (e.g., Heyman, 1983; Heyman et al., 1986; Heyman \& Seiden, 1985). However, although changes in the rate of leverpressing may have reflected alterations in both reinforcer efficacy and motor ability, there is no reason to expect that motor ability should have changed more greatly during responding in one component versus the other, thus obscuring a differential resistance to change. Changes in reinforcer efficacy, on its own, however, should still have produced changes in responding consistent with reinforcer-based forms of disruption such as extinction or prefeeding.

A more problematic effect of $d$-amphetamine was that, unlike other drugs in the present study, it impaired stimulus control to a significant extent across all subjects. The degrading of stimulus control was indicated by an increase in responding on the unsignaled (and therefore unreinforced) lever during signaling of the target component. This disruption in stimulus control creates a confound when one is trying to interpret $d$-amphetamine's effects because there is likely to be a loss of experimental control over the conditions maintaining different stimulus- 
reinforcer contingencies across components. If the stimuli signaling components are less discriminable (i.e., subjects respond more indiscriminately), then the component associated with the stronger baseline stimulus-reinforcer contingency is weakened, and the component associated with the weaker baseline stimulus-reinforcer contingency becomes strengthened (Nevin, 1992). As a result, here and in the study by Cohen (1986), the loss of stimulus control caused by $d$-amphetamine is likely to have obscured any difference in resistance to change established by baseline stimulus-reinforcer contingencies. This problem in assessing resistance to change when the stimulus-reinforcer contingencies have been compromised by a drug is similar to the problem that arises in using extinction as a means to disrupt responding (Harper \& McLean, 1992; Nevin et al., 1983). That is, the manipulation being used to disrupt responding also disrupts the conditions maintaining a differential resistance to change across components.

The suggestion that $d$-amphetamine failed to cause a greater change in responding associated with a weaker stimulus-reinforcer contingency because of confounding changes in stimulus control is supported by the finding that other drugs in the present study could produce these expected changes in responding at doses that did not affect stimulus control. For example, at the lowest dose tested, fluoxetine successfully produced a consistently greater increase in responding in the component associated with the weakest stimulus-reinforcer contingency.

The observation that fluoxetine, in particular, disrupted responding raises the issue of which neurochemical systems are important with respect to the biological basis of reinforcement. The disruptive effects of quinpirole suggest that even relatively specific increases in brain dopamine activity (at the D2 site, in particular) produce changes consistent with more generally acting dopamine antagonists (such as haloperidol and clozapine). However, although dopamine has traditionally been implicated as being of primary importance in reinforcement processes (e.g., Wise, 1982), the potential role played by other chemical systems has received less attention (Koob, 1992). Recently, recognition has grown of the importance of considering interactions between neurochemical systems. For example, many drugs that influence dopamine activity also effect the activity of serotonin (e.g., Lundberg, Lindstrom, \& Hartvig, 1989). Indeed, it may well be the case that the present effects of fluoxetine were the result of its primary site of action at serotonin receptors, rather than its indirect enhancement of dopamine levels. Consequently, there may be many classes of drugs, with different sites of action, which have similar effects with respect to resistance of reinforced responding to change (e.g., opioid drugs in Egli et al., 1992). It remains to be seen if different drug classes can be discriminated on the basis of quantitative differences in their effects on resistance to change.

Taken together, the previous results of Harper (in press) and the current study indicate that if stimulus control is uncompromised and an appropriate procedure is used for examining the role of stimulus-reinforcer contingencies in resistance to change, then a variety of drugs alter responding (either in terms of an increase or decrease) in a manner consistent with Nevin's resistanceto-change hypothesis. Therefore, these results present an important extension of the generality of Nevin's approach to include an account of the disruptive effect of drugs on reinforced responding.

In addition, the present results have other important implications. First, the finding that responding changed to a greater extent (when stimulus control was not compromised) in the component associated with the highest baseline rate of responding suggests that it is not baseline response rate per se that determines resistance to druginduced disruption. For example, the "rate-dependency principle" suggested by Dews and Wenger (1977) predicts that the lower the rate of baseline responding, the greater the change in responding following drug delivery. However, in the present study, the relatively greater change in responding occurred in the component associated with the highest baseline rate of responding but the smallest amount of reinforcement. This finding is consistent with the stance taken by researchers who have concluded that baseline rate of reinforcement, as opposed to baseline rate of responding, is the important independent variable determining the extent of change following delivery of a drug (e.g., Branch, 1984; Heyman \& Seiden, 1985).

Another implication of the present results follows from the method used, which allowed for a more precise statement about the role of reinforcement in determining the extent of disruption caused by drugs. Although the extent of disruption may depend on baseline reinforcement conditions, it appears that the extent of disruption specifically depended on the established Pavlovian stimulus-reinforcer contingencies (as opposed to operant response-reinforcer contingencies). Previous research has demonstrated that whereas response rate is determined by response-reinforcer contingencies, the resistance of responding to disruption depends on stimulusreinforcer contingencies (see Nevin, 1992). This, in turn, raises the question of what exactly is being disrupted when responding changes. For example, the drugs used here are unlikely to have acted to alter reinforcer efficacy in a generalized and unspecific manner, because such a change should also have compromised the different stimulusreinforcer contingencies established across components. Such a compromising of the independent variable did not happen (except in the case of $d$-amphetamine), and, therefore, responding in the two components showed differential resistance to change following drug delivery. One possibility is that changes in responding were caused by an alteration in the strength of the response-reinforcer contingency. Therefore, an issue that deserves further research attention is whether drugs can act to influence responding specifically at the level of the response-reinforcer contingency (thereby increasing or decreasing overall response rate), while leaving the stimulus-reinforcer contingency 
intact (thereby leaving the resistance of that responding to change intact).

\section{REFERENCES}

BraNCH, M. N. (1984). Rate dependency, behavioral mechanisms, and behavioral pharmacology. Journal of the Experimental Analysis of Behavior, 29, 447-452.

COHEN, S. L. (1986). A pharmacological examination of the resistanceto-change hypothesis of response strength. Journal of the Experimental Analysis of Behavior, 46, 363-379.

DEws, P. B., \& WENGER, G. R. (1977). Rate dependency of the behavioral effects of amphetamine. In T. Thompson \& P. B. Dews (Eds.), Advances in behavioral pharmacology (Vol. 1, pp. 167-227). New York: Academic Press.

Egli, M., SchaAl, D. W., Thompson, T., \& Cleary, J. (1992). Opioidinduced response-rate decrements in pigeons responding under variable-interval schedules: Reinforcement mechanisms. Behavioural Pharmacology, 3, 581-591.

Fouriezos, G., \& WiSE, R. A. (1976). Pimozide-induced extinction of intracranial self-stimulation: Response patterns rule out motor or performance deficits. Brain Research, 103, 377-380.

Gardier, A. M., Lepoul, E., Trouvin, J. H., Chanut, E., Dessalles, M. C., \& JACQUOT, C. (1994). Changes in dopamine metabolism in rat forebrain regions after cessation of long-term fluoxetine treatment. Life Sciences, 54, 51-56.

HARPER, D. N. (1996). Response-independent food delivery and behavioral resistance to change. Journal of the Experimental Analysis of Behavior, 65, 549-560.

HARPER, D. N. (in press). Behavioural resistance to haloperidol and clozapine. Behavioural Processes.

Harper, D. N., \& MCLEAN, A. P. (1992). Resistance to change and the law of effect. Journal of the Experimental Analysis of Behavior, 57, 317-337.

Heyman, G. M. (1983). A parametric evaluation of the hedonic and motoric effects of drugs: Pimozide and amphetamine. Journal of the Experimental Analysis of Behavior, 40, 113-122.

Heyman, G. M., Kinzie, D. L., \& Seiden, L. S. (1986). Chloropromazine and pimozide alter reinforcement efficacy and motor performance. Psychopharmacology, 88, 346-353.

Heyman, G. M., \& Seiden, L. S. (1985). A parametric description of amphetamine's effects on response rate: Changes in reinforcement efficacy and response topography. Psychopharmacology, 85, 154-161.

КоОв, G. F. (1992). Drugs of abuse: Anatomy, pharmacology and function of reward pathways. Trends in Pharmacological Sciences, 13, 177-184.

Ljungberg, T., Apicella, P., \& Schultz, W. (1992). Responses of monkey dopamine neurones during learning of behavioral reactions: Anhedonia, motor deficit, or both? Pharmacology, Biochemistry \& Behavior, 27, 341-350.

LUCKI, I., \& DELONG, R. E. (1983). Control rate of response or reinforcement and amphetamine's effect on behavior. Journal of the Experimental Analysis of Behavior, 54, 163-172.
LundBerg, T., Lindstrom, L. H., \& Hartvig, P. (1989). Striatal and frontal cortex binding of ${ }^{11} \mathrm{C}$-labelled clozapine visualized by positron emission topography (PET) in drug-free schizophrenics and healthy volunteers. Psychopharmacology, 99, 8-12.

Lyon, M., \& RoBisss, T. (1975). The action of central nervous system stimulant drugs: A general theory concerning amphetamine effects. In W. B. Essman \& L. Valzelli (Eds.), Current developments in psychopharmacology (Vol. 2, pp. 80-162). New York: Spectrum.

NEVIN, J. A. (1974). Response strength in multiple schedules. Journal of the Experimental Analysis of Behavior, 21, 389-408.

Nevin, J. A. (1984). Pavlovian determiners of behavioral momentum. Animal Learning \& Behavior, 12, 363-370.

Nevin, J. A. (1992). An integrative model for the study of behavioral momentum. Journal of the Experimental Analysis of Behavior, 57, 301-316.

Nevin, J. A., Mandell, C., \& Atak, J. R. (1983). The analysis of behavioral momentum. Journal of the Experimental Analysis of Behavior, 39, 49-59.

Nevin, J. A., Tota, M. E., Torquato, R. D., \& Shull, R. L. (1990). Alternative reinforcement increases resistance to change: Pavlovian or operant contingencies? Journal of the Experimental Analysis of Behavior, 53, 359-379.

OLDS, M. E., \& FOBES, J. L. (1981). The central basis of motivation: Intracranial self-stimulation studies. Annual Review of Psychology, 32, 523-574.

Philips, G., Willner, P., \& Muscat, R. (1991). Anatomical substrates for neuroleptic-induced reward attenuation and neuroleptic-induced response decrement. Behavioural Pharmacology, 2, 129-141.

Rolls, E. T., Rolls, B. J., Kelly, P. H., Shaw, S. G., Wood, R. J., \& DALE, R. (1974). The relative attenuation of self-stimulation, eating and drinking produced by dopamine-receptor blockade. Psychopharmacologia, 38, 219-230.

Salamone, J. D., Kurth, P., McCullough, L. D., \& Sokolowski, J. D. (1995). The effects of nucleus accumbens dopamine depletions on continuously reinforced operant responding: Contrasts with the effects of extinction. Pharmacology, Biochemistry \& Behavior, 50 , 437-443.

SANGER, D. J. (1986). Response decrement patterns after neuroleptic and non-neuroleptic drugs. Psychopharmacology, 89, 98-104.

STECKLER, T., \& SAHGAL, A. (1995). The role of serotonergic-cholinergic interactions in the mediation of cognitive behavior. Behavioural Brain Research, 67, 165-199.

TAYLOR, J. R., \& ROBBINS, T. W. (1984). Enhanced behavioural control by conditioned reinforcers following microinjections of $d$-amphetamine into the nucleus accumbens. Psychopharmacology, 84, 405-412.

Wise, R. A. (1982). Neuroleptics and operant behaviour: The anhedonia hypothesis. Behavioral \& Brain Sciences, 5, 39-87.

WISE, R. A., \& BOZARTH, M. A. (1987). A psychomotor stimulant theory of addiction. Psychological Review, 94, 469-492.

(Manuscript received March 6, 1998; revision accepted for publication September 17, 1998.) 